\title{
La Filosofía del Tiempo en Andrés Bello
}

Andrés Bello (Venezuela, 1781-1865) se adelantó a las corrientes del pensamiento hispánico hasta tal punto que sus contemporáneos no lo comprendieron y aun hoy los historiadores no se ponen de acuerdo cuando tratan de clasificarlo en un "ismo": eracionalismo, empirismo, idealismo, romanticismo?

Hace casi cuarenta años comenté la incomprensión de los románticos argentinos y chilenos que atacaron a Bello como si fuera un clasicista reaccionario. 1 Ahora quisiera examinar la filosofía de Bello a la luz de la de Kant para hacer ver que la teoria de los tiempos verbales en su Gramática de 1847 fue mucho menos racionalista de lo que se ha supuesto.

I. El tiempo en la filosofía moderna. En los siglos XVII y XVIII-la Edad de la Razón, de la Ilustración-disputaron dos corrientes filosóficas: Racionalismo y Empirismo. Los filósofos racionalistas-Descartes, Leibniz, Spinoza-creyeron que el universo era un mecanismo. Quisieron reducirlo a leyes y medirlo. Para ellos la realidad absoluta era eterna y el tiempo, un aspecto de la realidad física. En cambio los filósofos empiristas-Locke, Berkeley, Hume-, desentendiéndose de la metafísica, atribuyeron la temporalidad a los fenómenos de la experiencia humana. El conocimiento viene de la experiencia y sólo experimentamos una sucesión de impresiones e ideas. Racionalismo y Empirismo han de sintetizarse en el Idealismo de Kant.

II. El tiempo en Kant. Kant superó el dogmatismo racionalista y el escepticismo empirista. La realidad en sí (noúmeno) es incog- 
noscible: sólo conocemos fenómenos. En este conocimiento hay una materia, que nos es dada, y una forma, impuesta por nuestro yo. Toda experiencia se compone de un factor material provisto por percepciones sensoriales, y un factor formal, representado por conceptos. Conocemos porque las sensaciones se convierten en intuiciones al entrar en las formas de nuestra sensibilidad (el Espacio, medio de las yuxtaposiciones, y el Tiempo, medio de las sucesiones) y las intuiciones se convierten en conceptos al entrar en las formas de nuestro e ntendimiento (categorias de cantidad, cualidad, relación y modalidad). Ambas clases de formas, las de la sensibilidad y las del entendimiento, son a priori, esto es, no las aprehendemos ni por la experiencia ni por la inducción; son formas preexistentes que valen de antemano, son doncidiones necesarias y universales para que la realidad pueda aparecérsenos percibida y entendida. Estas formas a priori son, pues, "constitutivas" de nuestra experiencia del mundo. El conocimiento es una sǐntesis de dos operaciones heterogéneas: la intuición y el concepto. La intuición sensible se halla supeditada a dos formas de la intuición pura: el Espacio y el Tiempo. No son datos empüricos, transmitidos por nuestros sentidos, ni tampoco conceptos abstraídos. Si percibimos en el espacio y en el tiempo es porque ya disponemos de la visión del espacio y del tiempo. El espacio es la forma de la intuición de objetos externos que conceptuamos opuestos al "yo". El tiempo es la forma de la intuición de los hechos subjetivos, pero también de los objetivos. ¿Por qué? Porque la percepción de los objetos exteriores a nosotros (ordenados con la forma del espacio) ocurre en nuestra intimidad (que se ordena con la. forma del tiempo). El tiempo, pues, comprende al espacio. La forma del tiempo relaciona una multiplicidad de percepciones y afirma la unidad del espíritu humano.

III. Kant y Bello. Kant expuso sus ideas del espacio y el tiempo como formas a priori de la sensibilidad en Crítica de la razón pura (primera edición, 1781; segunda, modificada, 1787). No parece que Bello leyera en alemán. 2 Tampoco hay pruebas de que leyera la Critica en traducciones (al inglés en 1855; al francés, en 1864). Es muy probable que Bello conociera a Kant indirectamente, gracias al Cours d'histoire de la philosophie moderne de Victor Cousin, cuya primera parte apareció entre 1815 y 1830 . Sea lo que sea, lo cierto es que Bello mencionó a Kant como una de sus fuentes:

El percibir sucesivamente es propio de las inteligencias finitas ..... En este sentido es plausible la idea de Kant que mira el espacio y el tiempo como correlativos a 
las inteligencias humanas, como tipos a que amolda el hombre sus percepciones y conocimientos ("Psicología mental", IX, 163-64).

Leibniz ... negó al espacio y al tiempo no sólo el carácter de atributos divinos, sino el de cosas reales; reduciéndolos, como lo hemos hecho nosotros, a meras abstracciones o ideas. Kant pensaba de un modo semejante cuando los hizo condiciones a priori de todos nuestros conocimientos empíricos; pero condiciones subjetivas, esto es, propias de la inteligencia humana; molde a que adapta todas las nociones que le suministra la experiencia (X, 190).

Llámanse juicios y conocimientos empíricos o a posteriori los que se derivan lógicamente de la experiencia... Llamaremos juicios y conocimientos no empíricos o a priori, los que no se derivan lógicamente de la experiencia. Kant les atribuye estos dos caracteres: universalidad y necesidad .... El principio de la estabilidad de las leyes naturales ¿es en sî́ mismo un conocimiento a priori en el sentido de Kant? Creo que debemos responder que sí ("Lógica", I, 383-84).

IV. El tiempo en Bello. Las citas anteriores prueban que la Filosofia de Bello reflejaba luces de la Critica de Kant. Reflejaba también otras, si bien menos ilustres. Bello, como todo filósofo, aprovechaba los materiales que le eran accesibles y con ellos construía su propio pensamiento. A veces seguía la exposición, no de un genio, sino de una figura menor; digamos, no de Kant sino de Cousin. Pero reduciendo los materiales de Bello a un esquema simple-o sea, a la idea fundamental que se escondía en el fondo de lecturas y polémicas-es evidente que su filosofïa del tiempo se apoya en puntos que habìan sido avanzados por Kant.

Como Kant, Bello afirmó la indivisibilidad de la conciencia, idéntica a si misma en todos sus actos. "En cada uno de sus actos está el alma toda, el yo" (9). La actividad de la conciencia es creadora pues fabrica nuestra imagen del mundo. Sólo conocemos lo que está representado en la conciencia. Este conocimiento es una sǐntesis de materia y forma: una materia dada por nuestras percepciones y una forma constituida por nuestro entendimiento. Es "incontestable que hay en el entendimiento gran número de juicios y de conocimientos que lógicamente son anteriores a la experiencia, que lógicamente no se derivan de ella, ni por una derivación inmediata, ni por una deriva- 
ción ulterior, porque no puede haber experiencia que no los implique" (383).

Entre las deudas más importantes de Bello a Kant se cuenta la concepción de los principios a priori del conocimiento y de la idealidad del espacio y el tiempo. Por supuesto que los términos usados son diferentes. Kant había dicho que el espacio y el tiempo son formas a priori de la sensibilidad, condiciones que hacen posible nuestra experiencia. Pensando en lo mismo, Bello dirá que uno de los "fenómenos primordiales", uno de los "conceptos originales, primigenios, inexplicables" del poder inventivo del alma es la creación de las "relaciones elementales" de sucesión y coexistencia. A pesar de estas diferencias terminológicas, se encontrará en el capítulo octavo-"De la sucesión y la coexistencia"-una filosofía del tiempo, si no kantiana, por lo menos idealista.

Sólo en la conciencia, viene a decirnos Bello, se da la relación de sucesión. La realidad exterior al yo no se sucede a sí misma sino que, en el interior del yo, formamos la idea de sucesión. Es un error creer que algo real dura más o dura menos: lo que pasa es que el yo ordena las percepciones sucesivamente. El tiempo "nos parece tener una existencia independiente, separada, a que se refiere la existencia de todos los objetos que percibimos" (117), pero la verdad es que un tiempo deshumanizado, fuera del mundo de nuestras percepciones, es una mera abstracción. "Siguese de aquí que el tiempo es una hechura de la imaginación" (117). Tiempo real es el tiempo "hecho" por el hombre. Nuestra imaginación lo fabrica y luego lo proyecta sobre el universo. Hay, pues, dos clases de tiempo. Un tiempo concebido como si estuviera fuera de la conciencia, tiempo físico, mensurable; $y$ el tiempo indivisible de la conciencia, psicológico e inmensurable.

V. Los tiempos verbales. De esta filosofía idealista del tiempo se desprendió la teoría de los tiempos verbales que Bello sistematizó en su Gramática de la lengua castellana para uso de los americanos (Santiago de Chile, 1847). Amado Alonso, que en un espléndido análisis exaltó su modernidad en el siglo XIX y su vigencia en el siglo XX, creía que justamente en el tema de los tiempos verbales Bello se habia quedado cerca "del racionalismo de la gramática lógica general". 3 Quizá Alonso haya exagerado la filiación racionalista francesa de la ideología gramatical de Bello: "Hemos de reconocer que sin el principio de Port-Royal [el de los verbos como fechaciones, en la Grammaire de 1660] nuestro autor no habría podido siquiera iniciar el estudio de su sistema" (pág. lxii). 
¿Y si Bello fue más kantiano o al menos más idealista de lo que Alonso sospechó? Entonces ¿qué?

La filosofía racionalista, sin reparar en que estaba tomando vistas instantáneas sobre la duración vivida por una persona individual, reducía el tiempo a una trayectoria de puntos: el pasado, el presente, el futuro eran meras abstracciones. Calcada sobre esa filosofía, la gramática racionalista concibió los tiempos verbales como fechas en relación con esa línea. A un tiempo con pasado, presente y futuro debǐan corresponder, lógicamente, formas lingüisticas que apuntaran a ese pasado, a ese presente y a ese futuro. El punto de referencia era el instante de la palabra. La filosofïa implícita en las gramáticas racionalistas afirmaba:

a) la existencia objetiva del tiempo como dirección lineal;

b) el punto-instante del ahora que divide el tiempo en un antes y un después; $y$ bales.

c) la significación exclusivamente fechadora de los tiempos ver-

De acuerdo, pero el caso es que para Bello el tiempo no era una realidad objetiva sino una creación humana. Distingula entre tiempo físico y tiempo psicológico: habrá sucesiones en el mundo fỉsiconatural, concedia, pero sólo percibimos las que se dan en la conciencia. Aunque ponemos fechas a la sucesión de hechos que observamos en la naturaleza, en verdad los tiempos verbales no fechan sino que se refieren a la actividad de la conciencia, la cual, comparando dos percepciones, engendra la relación de un antes o un después. Calcada sobre la filosofía idealista que instaló el tiempo en la conciencia, la gramática de Bello definió los tiempos verbales no como funciones fechadoras en la línea de un tiempo objetivo sino como expresiones que revelan la perspectiva y la actitud del hablante.

Aun la concepción del verbo cambió al pasar del racionalismo al idealismo. Los racionalistas habían identificado la lengua con la lógica. Sostenían que las partes de la oración se ajustaban a partes de la realidad. Así, el verbo correspondía a acciones. Por el contrario los idealistas observaron que los oficios de las palabras dependen de nuestra intención personal en el momento de hablar y que el acto de hablar es manifestación de la temporalidad de nuestra existencia. Pues bien, la definición de verbo y tiempo verbal que da Bello en su Gramática no difiere esencialmente de la que, inspirada en una filosofía idealista del lenguaje, dan Amado Alonso y Pedro Henríquez Ureña en su Gramática castellana (Buenos Aires: Libreria El Ateneo, 1938). Ambas definiciones insisten en que el verbo es una palabra 
mediante la cual el hablante piensa la realidad como un comportamiento del sujeto de la oración. No es que el verbo apunte a una realidad en acción, sino que la piensa en accióm. Ambas definiciones insisten en que los tiempos verbales distinguen entre presente, pretérito y futuro según la relación que los acontecimientos-anteriores, posteriores-guarden con el momento presente del hablante. Habria tres puntos de referencia (al adoptar el cuadro de Amado Alonso sólo expondré las formas del Indicativo):

Primer punto de referencia es el instante mismo de hablar llamado Presente (vivo). Lo anterior es Pretérito (vivǐ). Lo posterior es futuro (viviré). Estos tiempos son absolutos.

Segundo punto de referencia es uno de los tres tiempos arriba mencionados, respecto al cual el nuevo tiempo puede significar anterioridad, coexistencia o posterioridad: Ante-pretérito (hube vivido); Co-pretérito (vivia); Pos-pretérito (vivirìa); Ante-presente (he vivido); Ante-futuro (habrá vivido). Estos tiempos son relativos.

Tercer punto de referencia es un tiempo ya relativo (vivìa, viviria) respecto al cual un nuevo tiempo de nuestra conjugación significa anterioridad: Ante-co-pretérito (habia vivido) y Ante-pospretérito (habrĭa vivido).

Obsérvese que estos tres puntos de referencia no se desplazan en un tiempo objetivo, como en las gramáticas que continuaban la tradición de los autores de Port-Royal, sino que están vividos por un hablante concreto, de carne y hueso. En "Significación de los tiempos" (nota XIII a su Gramática) Bello explicó el origen de su nomenclatura, origen para mí más idealista que racionalista:

Las formas verbales, o expresan una relación simple de coexistencia, anterioridad o posterioridad respecto del acto de la palabra, esto es, respecto del momento en que se profiere el verbo, o expresan combinaciones de dos o más de estas mismas relaciones; y el nombre que doy a cada forma denota esa misma simplicidad o composición. Cuando la relación es una, la expreso con las palabras presente, pretérito, futuro. Si la relación es doble, antepongo a estas mismas palabras una de las partículas co, ante, pos, que significan respectivamente coexistencia, anterioridad, posterioridad. Así la denominación co-pretérito significa coexitencia con una época que se mira en tiempo pasado, y ante-futuro denota anterioridad a una época que se mira en tiempo futuro .... Ante-futuro significa anterioridad a un 
futuro, y pos-pretérito posterioridad a un pretérito, siendo siempre el acto de la palabra el punto final en que termina la serie de relaciones, cualquiera que sea su número $(379-80)$.

Esta explicación de la Gramática de la lengua castellana está explicada, a su vez, en la Filosofía del entendimiento. Hay que articular ambas obras para comprender la profundidad de Bello. Los tres puntos de referencia y sus prefijos co, ante y pos, sistematizados en la Gramática, corresponden a las "percepciones relativas" de la Filosofía, en cuyo capítulo octavo, sobre la coexistencia y la sucesión, se sostiene que percibimos de un modo inmediato relaciones entre un ahora, un antes y un después. Y en el capítulo XIX sobre la memoria Bello añade: "Anterior, posterior, coexistente expresan relaciones simples, objetos de percepciones inmediatas. Pasado, presente, futuro presuponen la noción general de tiempo, que formamos agregando relaciones elementales de sucesión" (313). Esta experiencia de la temporalidad es-como ya vimos-"uno de los fenómenos primordiales del entendimiento"; en términos kantianos, una forma a priori de la sensibilidad. La escuela idealista-dice Bello-"tuvo razón para mirar la idea de la duración del tiempo como un producto peculiar de la actividad del alma" (121).

Poco racionalista, muy psicologista fue Bello cuando puntualizó que los tiempos verbales son perspectivas del hablante: uno de sus ejemplos fue el hecho de que hay tiempos relativos a otros tiempos relativos, como "habìa vivido", "habrìa vivido". Y aun más psicologista fue cuando acentuó la importancia de tiempos verbales con significación secundaria y metafórica, a saber:

Significaciones secundarias. Del significado propio y fundamental de las formas indicativas se derivan los significados secundarios por medio de transformaciones sujetas a una ley constante. Uno de los significados secundarios-peculiar a las formas que envuelven relación de coexistencia: vivo, vivia, he vivido, había vividocorre su significación un punto hacia adelante en la línea del tiempo. He aquï dos casos:

a) cuando, precedidos de $s i$, forman frases hipotéticas ("Si el cielo me da fuerzas para tanto, cantaré aqui'"; "si ha venido ya nuestro amigo, convidadle");

b) cuando se declara con ellos el objeto de una percepción, creencia o aserción ("Veo que le han partido por medio del cuerpo", etc.). O sea, que precediendo la frase con el convencional si, el pre- 
sente (vivo) pasa a futuro (viviré); y el co-pretérito (vivia) a pospretérito (viviria). El ante-pretérito (he vivido) se hace ante-futuro (Habré vivido) y el ante-co-pretérito (habia vivido) se hace ante-pospretérito (habría vivido).

Significados metafóricos. Presente histórico ("San Martîn cruza los Andes"). Presente con valor de futuro ("mañana voy al campo"). Presente que confiere al pasado y al futuro viveza mental ("Le digo que se calle y ella me contesta que no se le da la gana, entonces le pego y ella llora a gritos, se va a casa de su madre y al mes vuelve peor que antes"). El futuro como tiempo de probabilidad ("Ahora serán las cinco de la tarde"; "tendrìa entonces veinte años"; "ya habrá llegado a su casa"). Este futuro transporta su propia incertidumbre al presente o al pasado. Etc.

Aunque Amado Alonso, refiriéndose a la Gramática de Bello, juzgó que "quizá lo más cuestionable para el estado actual de nuestros conocimientos sea la concepción del tiempo" (pág. lxvii), no se le escaparon las implicaciones psicológicas en los ejemplos de tiempos verbales que acabamos de repasar. Si. Alonso supo apreciar frases como ésta: "El tiempo es una hechura de la imaginación"; y, con característica finura, presentó a Bello adelantándose a los gramáticos, no sólo del siglo XIX, sino también del siglo XX, como Otto Jespersen: "Asombrado se queda uno ante alguna de las profundas zambullidas en un estilo de examen que sólo el siglo XX desarrollarǐa" (pág. lxxii). Y citó este pasaje de la Gramática:

Poniendo al co-pretérito [vivia] en relación con el pretérito [viví] ¿se pueden expresar con él, no sólo las cosas que todavía subsisten, sino las verdades de duración indefinida o eterna? ¿Y no será impropio decir: "Copérnico probó que la tierra giraba alrededor del sol"? Si es exacta la idea que acabo de dar del co-pretérito la expresión es perfectamente correcta. Podría tolerarse gira, mas entonces no veriamos por entre la mente de Copérnico $\mathrm{el}$ giro eterno de la tierra, como el sentido lo pide (181).

La significación del co-pretérito giraba no es, en este último caso, el girar de la tierra, sino la representación del girar de la tierra en una mente. Asǐ y todo, Amado Alonso adjudica a Bello la teoría de que el tiempo es una realidad objetiva y que esa realidad consiste en un punto-instante incesantemente transitorio cuya carrera forma la linea del tiempo. Habiéndole adjudicado esa filosofía racionalista, supone luego que la concepción del presente con que Bello opera es la que William James y otros psicólogos han rechazado (lxviii-lxix). 
William James observó en Principles of Psychology (1890) que hay un "tiempo especioso" o engañoso: presente que dura cuando, por ejemplo, oimos una melodía y no sentimos que ninguna de sus frases sea un pasado. Pues bien, si no me equivoco, ya Bello lo habia observado. En el capitulo segundo de su Filosofia del entendimiento hay frases de psicología anti-asociacionista que, traducidas al inglés, sonarian semejantes a las que William James escribirá mucho después: "specious present", "stream of consciousness", etc. Una muestra:

El alma humana puede experimentar, no sólo dos, sino innumerables afecciones y modificaciones a un mismo tiempo. Esta multitud de estados espirituales contemporáneos es un hecho permanente, o por mejor decir, continuo. Probablemente uno solo de ellos fijará la atención de un modo vivo en un instante dado; mas, no por eso dejarán de existir en ese mismo instante los otros.... Hay percepciones vivas, atentas; y percepciones débiles, fugitivas. De las segundas hay un número incalculable a cada momento (28-31).

Y a continuación, al hablar de "la conciencia de la conciencia", Bello se refiere a esas percepciones que se prolongan, se meten unas en otras y duran hasta que, naturalmente, acaban por debilitarse: ¿no es esto "el presente especioso"?

Harvard University

ENRIQUE ANDERSON IMBERT

\section{NOTAS}

1. "Andrés Bello, Sarmiento y la Generación de 1842", La Nación, Buenos Aires, 6-XII-1942. Recogï este artículo en Los domingos del profesor, Buenos Aires: Gure, 1972.

2. Véanse las investigaciones de José Gaos, "Introducción" a Filosofía del entendimiento de Andrés Bello (México: Fondo de Cultura Económica, 1948) y Juan David García Bacca, "Prólogo" a Filosofía de Andrés Bello en Obras completas (Caracas: Ministerio de Educación, 1951), III. La primera edición de Filosofía del entendimiento, póstuma, es de Chile, 1881. En las citas que haga los números de página corresponderán a la edición oficial de Caracas, 1951.

3. "Introducción a los estudios gramaticales de Andrés Bello" en Gramática por Andrés Bello, Obras completas (Caracas: Ministerio de Educación, 1951), vol. IV, pág. xli. 
